\title{
La buena administración como fundamento de actuación del empleado público
}

Pedro Padilla Ruiz

DOI: https://doi.org/10.47623/ivap-rvap.108.2017.12

\begin{abstract}
Sumario: I. Introducción: la buena Administración como nuevo intento para encauzar la actuación administrativa hacia el ciudadano.II. El Estatuto Básico del Empleado Público y su apuesta por la buena Administración. II.1. La conducta profesional y su conexión con el deber de buena Administración. II.2. La relación entre el derecho a una buena Administración y la evaluación del desempeño del empleado público.-III. Conclusiones.-IV. Bibliografía.
\end{abstract}

\section{Introducción: la buena Administración como nuevo intento para encauzar la actuación administrativa hacia el ciudadano}

Parece una obviedad pensar que la Administración Pública debe ser coherente con sus fines, tener presente en todo momento sus principios de actuación y proceder con ética y pensando en los ciudadanos, que son sus destinatarios finales(1). Sin embargo y por desgracia, esto no siempre es así; en ocasiones olvida su fundamento de actuación, produciéndose desviaciones no deseadas que obligan a incidir una y otra vez en aquellos principios y en la necesidad de encauzar determinadas prácticas que se suelen denominar de "mala Administración».

Esto ha llevado a la creación de nuevos derechos o principios de actuación como el de buena Administración, que aparecen ante la necesidad de conseguir, o más bien de renovar, la incesante búsqueda de esa Administración eficaz y eficiente que todos buscamos. Se trata de un concepto que no hemos de confundir con otro similar y también de aplica-

(1) Cfr. ÁVILA RODRíGUEZ, Carmen María y GUTIÉRREZ RODRíGUEZ, Francisco J.: El derecho a una buena Administración y la ética pública, Tirant lo Blanch, Valencia, 2011. También GÁMEZ GÁMEZ, José Antonio: El derecho a una buena Administración desde la perspectiva de la ética pública: el buen gobierno y la buena conducta administrativa, 2009. 
ción actual en el desarrollo de dichos objetivos, denominado de buena Gobernanza, de carácter más amplio y en el que participan distintas partes junto a la Administración. El de buena Administración, por su parte, queda más restringido al ámbito interno de actuación de las organizaciones públicas y por tanto, y como veremos, se encuentra más relacionado con la actuación del empleado público (2).

Como ha destacado CERRILLO I MARTÍNEZ, la diferencia entre ambos conceptos es que los «principios de buena administración se dirigen a los funcionarios y personal de los organismos públicos y regulan sus relaciones con los ciudadanos $y$, por tanto, tienen un ámbito más específico que los principios de buena gobernanza, que se refieren a las relaciones entre actores políticos» (3). Se da así una nueva vuelta de tuerca en la siempre complicada evaluación de la Administración y la incorporación de nuevos conceptos a su acervo.

Desde sus orígenes, a través del concepto clásico de buen gobierno, la acción administrativa ha venido presidida, al menos desde un punto de vista teleológico, por la intención de adecuarse a las necesidades de los ciudadanos y de la sociedad en su conjunto, equilibrando el interés particular con el general. Sin embargo, esto no ha sido siempre fácil, pues como postula VILLORIA MENDIETA, en una sociedad cada vez más individualista chocan a menudo las exigencias particulares con la búsqueda del bien común(4). De este modo, se establecieron una serie de normas y

(2) A los meros efectos expositivos hablaremos de empleados públicos para hacer referencia tanto a los hombres como a las mujeres que forman parte de las Administraciones Públicas. En el mismo sentido aglutinador utilizamos el sustantivo neutro ciudadano, funcionario, etc. para referirnos a ambos sexos.

(3) CERRILLO I MARTÍNEZ, Agustí: La gobernanza hoy: 10 textos de referencia, $1 .^{\text {a }}$ edic., INAP, Madrid, 2005. p. 20. Se puede realizar una mayor aproximación a la buena Administración, entre otros, a través de AMILIVIA GONZÁLEZ, Mario y NALDA GARCÍA, José C.: "Principios de buena Administración y función consultiva», en Revista española de la función consultiva, n. ${ }^{\circ}$ 9, 2008, pp. 17-30, DíAZ MUIÑA, Manuel y MURILLO GARCÍA-ATANCE, Ignacio: "La ética administrativa: elemento imprescindible de una buena Administración", en Revista Aragonesa de Administración Pública, n. ${ }^{\circ} 32,2008$, pp. 133-170, LORENZO DE MEMBIELA, Juan B.: "La buena administración como estrategía promotora de la excelencia gestora», en Revista Aragonesa de Administración Pública n. ${ }^{\circ}$ 30, 2007, pp. 445-458, MEILÁN GIL, José Luis: "La buena Administración como institución jurídica», en Administración de Andalucía: revista andaluza de administración pública, $\mathrm{n} .{ }^{\circ}$ 87, 2013, pp. 13-50, MEMBIELA, Juan B. Lorenzo: «La buena administración en la Administración General del Estado», en Actualidad administrativa, n. ${ }^{\circ} 4,2007$, pp. 405414, RODRÍGUEZ-ARANA MUÑOZ, Jaime. "El derecho fundamental a la buena Administración en la Constitución española y en la Unión Europea», en REGAP: Revista galega de Administración Pública, n. ${ }^{\circ}$ 40, 2010, pp. 235-264, RODRÍGUEZ-ARANA MUÑOZ, Jaime: "Ética pública y buena Administración de instituciones públicas», en Revista de estudios locales. Cunal, n. ${ }^{\circ}$ 98, 2007, pp. 14-21, RODRÍGUEZ-ARANA MUÑOZ, Xaime: «El derecho fundamental al buen gobierno y a la buena Administración de instituciones públicas», en Revista de derecho público, n. ${ }^{\circ} 113,2008$, pp. 31-42.

(4) VILLORIA MENDIETA, Manuel: La modernización de la Administración como instrumento al servicio de la democracia, INAP, Madrid, 1996. p. 131. 
principios procedimentales y de actuación que redundaran en la más eficaz y apropiada, en términos generales, atención de dichos intereses (5).

La buena Administración se ha convertido en los últimos años en un referente en la acción administrativa (6), sobre todo a partir de la Carta de los Derechos Fundamentales de la Unión Europea (CDFUE) de 2000 o Carta de Niza (7), que la incluyó como derecho fundamental(8). Este principio o derecho, que como un deber de actuación de amplio rango impuesto a la Administración de manera abstracta, se ha ido perfilando poco a poco, no solo ha incluido en su seno un conjunto de deberes y derechos concretos que ya existían anteriormente como tales, relativos al procedimiento administrativo en general (motivación de los actos admi-

(5) El deber de buen gobierno o el más actual de buena Administración ya lo encontramos como concepto - más bien teórico - en textos clásicos de Platón, Cicerón, Aristóteles o Sócrates, cuando se referían a la necesidad de que los gobernantes buscasen el interés general y en definitiva, el bienestar de los ciudadanos. Con esta misma expresión tenemos referencias en nuestro Ordenamiento, como por ejemplo en el número extraordinario de la Gaceta de Madrid de 19 de marzo de 1820, donde se daba cuenta del Decreto Real de convocatoria del "Consejo de Estado, cuya asistencia es necesaria para las determinaciones que exige el buen gobierno de los pueblos». De más antigua es la referencia que hace la Gaceta de Madrid del 24 de junio de 1796 dando cuenta de diversas órdenes de buen gobierno y policía dictadas en Milán. O la mención a la actividad del Rey en el mantenimiento del «buen gobierno de efte Reyno", hecha en la Gaceta de 21 de febrero de 1736. Todos estos documentos pueden consultarse en el portal web del BOE: www.boe.es. Pese a esos contornos abstractos en que se mueven los conceptos de buen gobierno o buena Administración podemos encontrar en nuestra legislación una definición de ese primer término, y concretamente en el artículo 2.d) de la Ley 19/2014, de 29 de diciembre, de transparencia, acceso a la información pública y buen gobierno, de la Comunidad Autónoma de Cataluña: «Buen gobierno: los principios, obligaciones y reglas sobre la calidad de los servicios y el funcionamiento de la Administración, y los principios éticos y buenas prácticas de acuerdo con los que deben actuar los altos cargos de la Administración, los cargos directivos y demás personal al servicio de la Administración, con el objetivo de que esta funcione con la máxima transparencia, calidad y equidad, y con garantía de rendición de cuentas».

(6) Encontramos la primera referencia al término «buena Administración», referida a la Justicia, en la Jurisprudencia europea de la Sentencia del Tribunal Europeo de Derechos Humanos de 26 mayo 1988, Caso Ekbatani contra Suecia. (TEDH 1988/10), dentro de uno de los votos disidentes, poniéndolo en relación con «las necesidades de una administración de justicia rápida y económica por lo general». En referencia a la buena Administración propiamente dicha (excluida la de justicia) vemos una primera inclusión del concepto en la Sentencia del Tribunal de Primera Instancia de las Comunidades Europeas (Sala Primera) de 9 de noviembre de 1994. Caso The Scottish Football Association contra Comisión de las Comunidades Europeas (TJCE 19941191). En tal sentido, la entrada en vigor del Tratado de Maastricht dio lugar al concepto de ciudadanía europea, lo que supuso la aparición no solo de una serie de derechos ciudadanos sino de una serie de obligaciones para sus instituciones y la consiguiente creación de la figura del Defensor del Pueblo Europeo (Ombudsman) con unas funciones similares a las de sus homólogos nacionales en la defensa de los derechos de los ciudadanos de la Unión.

(7) Proclamada formalmente por el Parlamento Europeo, la Comisión y el Consejo en diciembre de 2000. Carta que fue enmendada y proclamada nuevamente en 2007 con el fin de poder formar parte del Tratado de Lisboa, por el que se modifican el Tratado de la Unión Europea y el Tratado Constitutivo de la Comunidad Europea (Diario Oficial de la Unión Europea, Serie C, de 17 de diciembre de 2007), y que entró en vigor en diciembre de 2009, adquiriendo el mismo peso jurídico que el resto de Tratados europeos. Dicha Carta forma parte del Tratado por el que se establece una Constitución para Europa como Parte II del mismo.

(8) GUILLEM CARRAU, Javier: "La buena administración en la UE tras el Tratado de Lisboa: ¿más por menos?", en Corts: Anuario de derecho parlamentario, n. ${ }^{\circ} 25,2011$, pp. 69-103. 
nistrativos, deber de notificar, acceso a archivos...) sino también unos principios más generales de actuación donde destacan la eficacia y la eficiencia, que se venían imponiendo a aquella prácticamente desde las primeras regulaciones serias del Derecho Administrativo (9).

Como recuerda RODRÍGUEZ-ARANA, la buena Administración es aquella que sirve "con racionalidad, justificando sus actuaciones y que se orienta continuamente al interés general, tratando de mejorar de manera continua el bienestar público» (10).

Por ello, lo que ha supuesto la buena Administración ha sido la unificación de esos derechos en un único concepto(11), en un "cesto" en función de esa finalidad común con el objeto primordial de reconocer la importancia del ciudadano y de poder "manejar» bajo un mismo paraguas un conjunto heterogéneo de derechos y principios, ofreciendo respuestas rápidas, económicas y eficaces a aquel(12), creando un principio o derecho informador de la actuación pública, lo que por otro lado plantea problemas de invocación ante los Tribunales(13).

Por su parte, en nuestro ordenamiento la Constitución de 1978 no menciona el derecho a la buena Administración como tal, ante todo por ser anterior a su reconocimiento, pero sí al menos debemos considerar que figura de manera implícita al incluir sus principios informadores en el artículo 103.1, o en el 105.c), como ha tenido ocasión de declarar el Tribunal Supremo en Sentencias como la de 20 de enero de 2014 (F.J. 2. ${ }^{\circ}$ ) o la de 19 de octubre de 2016 (F.J. 1. ${ }^{\circ}$ ), respectivamente(14):

(9) Sobre la relación entre procedimiento administrativo y buena Administración puede leerse a DÍAZY DÍAZ, María Cruz: El empleado público ante el procedimiento administrativo: deberes y obligaciones de buena administración, La Ley. Grupo Wolters Kluwer., 2011.

(10) RODRÍGUEZ-ARANA MUÑOZ, Jaime: El derecho a una buena administración para los ciudadanos: un modelo global de administración, Netbiblo, INAP, La Coruña-Madrid, 2013. p. 18

(11) Sobre su naturaleza jurídica se discute si se trata de un derecho fundamental, ordinario, o si es un principio rector de la actuación de la Administración. En particular, TOMÁS MALLEN considera que se trata de "una especie de derecho-garantía o derecho instrumental, que propicia la defensa de otros derechos»:TOMÁS MALLÉN, Beatriz: El derecho fundamental a una buena administración, 1. ${ }^{a}$ edic., INAP, Madrid, 2004. Para TORNOS sería un «mandato de optimización» impuesto a la Administración: TORNOS MAS, Joaquín: El derecho a una buena administración [recurso electrónico], Barcelona, Sindicatura de Greuges de Barcelona, 2007, p. 38 y ss. También es de sumo interés la lectura de CARRILLO DONAIRE, Juan Antonio: «Buena administración, ¿un principio, un mandato o un derecho subjetivo?», en SANTAMARÍA PASTOR Juan Alfonso (Dir.), Los principios jurídicos del Derecho Administrativo, La Ley, Madrid, 2010, pp. 1137-1165.

(12) TOMÁS MALLÉN, Beatriz: El derecho fundamental a una buena administración, 1. ${ }^{a}$ edic., INAP, Madrid, 2004. p. 41 y ss.

(13) FUENTETAJA PASTOR, Jesús Angel: «El derecho a la buena administración en la Carta de los Derechos Fundamentales de la Unión Europea», en Revista de derecho de la Unión Europea, n. ${ }^{\circ} 15$, 2008, pp. 137-154. p. 151.

(14) También la STS de 2 junio 2009, F.J 10. ${ }^{\circ}$ : «derecho al procedimiento debido y a la buena Administración, que institucionaliza el artículo 103». Por otra parte, la Carta Magna ha incluido los principios informadores de la buena Administración también en su artículo 9.2, que obliga a los poderes públi- 
"...el mandato constitucional contenido en el artículo 103 de la Constitución, a cuyo tenor la Administración Pública, que sirve con objetividad los intereses generales y actúa de acuerdo con el principio de eficacia y con sometimiento pleno a la Ley y al Derecho, le impone el deber de «buena administración", que comporta que en la tramitación de los expedientes administrativos respete las reglas y garantías establecidas en la Ley 30/1992, de 26 de noviembre, de Régimen Jurídico de las Administraciones Públicas y del Procedimiento Administrativo Común.».

Tal exposición no deja margen de duda para considerar la importancia de ese derecho como fundamento de actuación del empleado público, íntimamente ligado a la eficacia, como también ha reconocido el Tribunal Constitucional (15), y de lo que fácilmente podemos concluir que la actuación del empleado público juega un papel esencial en la consecución de tal principio, que a la sazón ha sido incorporado a diversos Estatutos de Autonomía y a la legislación ordinaria (16).

Tampoco hemos de olvidar que será en el procedimiento administrativo donde la actuación del empleado público se va a hacer más patente

\footnotetext{
cos a permitir la participación ciudadana en los asuntos públicos; en el artículo 23.1, sobre el derecho de participación de los ciudadanos en los asuntos públicos; en el artículo 105.b, sobre acceso de los ciudadanos a los archivos y registros; o en el 105.c, que exige la regulación legal del procedimiento administrativo. Será la legislación ordinaria la que establezca de manera más concreta los principios de actuación de la Administración; principios que por otro lado vienen siendo comunes y no suelen ofrecer discusión por tratarse de conceptos consolidados en las democracias occidentales.

Por su parte, podemos destacar también la temprana STS de 5 marzo 1979, que relacionaba eficacia administrativa con buena Administración.
}

(15) STC 93/2012 y 98/2012, de 7 de mayo. En ambos casos en su Antecedente $3 .^{\circ}$, donde ponen en conexión la buena Administración y la eficacia en relación con la falta de respuesta en plazo por parte de la Administración, y por tanto con el principio de celeridad.

(16) Así, por ejemplo, entre los Estatutos de autonomía, Ley Orgánica 14/2007, de 30 de noviembre, en Castilla León; Ley Orgánica 2/2007, de 19 de marzo, en Andalucía; Ley Orgánica 1/2007, de 28 de febrero, en Baleares; Ley Orgánica 1/2011, de 28 de enero, en Extremadura; Ley Orgánica 6/2006, de 19 de julio, en Cataluña; la Ley Orgánica 1/2006, de 10 de abril, en Valencia; Ley Orgánica 7/2010, de 27 de octubre, de reforma de la Ley Orgánica 13/1982, de 10 de agosto, de reintegración y amejoramiento del Régimen Foral de Navarra.

Entre otras, podemos también mencionar las siguientes normas de rango legal. Real Decreto Legislativo $3 / 2011$, de 14 de noviembre, por el que se aprueba el texto refundido de la Ley de Contratos del Sector Público. En similares términos el artículo 4 de la antigua Ley 13/1995, de contratos de las Administraciones Públicas. Ley 11/2008, de 3 de julio, de participación ciudadana de la Comunidad Valenciana. Ley $8 / 2010$, de 30 de agosto, de ordenación del sistema de salud de Castilla y León. Ley $5 / 2010$, de 27 de diciembre, de medidas extraordinarias para la sostenibilidad de las finanzas públicas, de la región de Murcia. Menciona los principios de la buena Administración en su exposición de motivos como fin al que debe llegarse a través de mayores controles en el gasto público, Llama, sin embargo, la atención, que no haga ni una sola referencia a principios tan elementales en materia financiera como el de eficiencia. Ley 4/2011, de 31 de marzo, de la buena Administración y del buen gobierno de las Islas Baleares. 
frente al ciudadano, quien siendo destinatario final de los bienes y servicios administrativos tiene derecho y puede exigir un actuar diligente y conforme a los requisitos de la buena Administración. De hecho, uno de los grandes bloques en que se configura este nuevo principio/derecho, $y$ que recuerda PONCE SOLÉ, es el de los Derechos del ciudadano en el procedimiento administrativo (17).

La buena Administración ofrece una idea exacta del carácter central que adopta la figura del ciudadano en el entorno de la acción administrativa como eje sobre el que gira su existencia y como concepto a tener en cuenta de manera activa. El ciudadano es protagonista en el desarrollo y razón de ser de la propia Administración, es su "cliente» en muchos ámbitos, y al igual que en el entorno privado, hay que cuidarle, respetarle y escucharle, pero con la particularidad de que la propia Administración le pertenece, por lo que existe un plus en la exigencia de un buen funcionamiento en el sentido más amplio. La buena Administración se sitúa en un ámbito nuevo en el que se ha pasado de no contar con los ciudadanos a que estos sean pieza clave de la actuación Administrativa y donde coincidimos con BAENA DEL ALCÁZAR cuando indica que "la Administración debe seducir a su público" (18).

Como señala PONCE SOLÉ, el «deber jurídico de buena Administración queda convertido en una auténtica obligación jurídica mediante la legislación procedimental común, que contiene, en consecuencia, un derecho de los interesados, e incluso de los ciudadanos en general, en determinados casos, al procedimiento administrativo debido" (19).

\section{El Estatuto Básico del Empleado Público y su apuesta por la buena Administración}

La ordenación del empleo público siempre ha sido uno de los puntos débiles de la estructura administrativa española, lo que se ha reflejado en los problemas que ha venido arrastrando en cuanto a su funcionamiento

(17) «El procedimiento administrativo se configura, así, como uno de los instrumentos jurídicos posibilitadores del cumplimiento del deber de buena Administración, como un factor, por tanto, de potenciación de las posibilidades de obtención de decisiones administrativas de calidad y, en definitiva, como un elemento de legitimación de las Administraciones Públicas». PONCE SOLÉ, Julio: Deber de buena Administración y derecho al procedimiento administrativo debido: las bases constitucionales del procedimiento administrativo y del ejercicio de la discrecionalidad, 1. ${ }^{a}$ edic., Lex Nova, Valladolid, 2001. p. 127.

(18) BAENA DEL ALCÁZAR, Mariano: Curso de Ciencia de la Administración, Vol. I, 4. a edic., Tecnos, 2000. p. 123.

(19) PONCE SOLÉ, Julio: Deber de buena Administración y derecho al procedimiento administrativo debido: las bases constitucionales del procedimiento administrativo y del ejercicio de la discrecionalidad, 1. ${ }^{\text {a }}$ edic., Lex Nova, Valladolid, 2001., p. 41. 
a la hora de dar respuesta a las necesidades de la sociedad y en particular en el modo de actuar y lograr una verdadera satisfacción del ciudadano. Tampoco hace falta recordar que nos hemos regido hasta bien pasada la aprobación de nuestra Constitución por normas preconstitucionales y por soluciones parciales (véase la LMRFP) y poco decididas, y que cuarenta años después del mandato del artículo $103 \mathrm{CE}$, cuando por fin y tras algún que otro intento fallido(20), se ha aprobado un verdadero Estatuto del Empleado Público, aún continúan en gran medida los problemas que el empleo público viene arrastrando.

No obstante, el EBEP, al menos en su intención, ha apostado fuerte por dotar a las Administraciones de las herramientas necesarias para hacerlas más eficaces, eficientes e incluso competitivas, incorporando - entre otros - los principios de la buena Administración, pues como indica PADILLA RUIZ, «con los postulados del EBEP y la buena Administración se da respuesta de manera más decidida a la eficiencia y a la mencionada satisfacción del ciudadano; satisfacción que pasa por recibir un trato exquisito y controlable mediante la evaluación» (21).

La trascendencia de contar con un personal al servicio de la Administración que esté bien preparado, adecuadamente motivado e imbuido del sentido de servicio público es esencial en cualquier contexto de funcionamiento de aquella, pero hoy en día con más énfasis debemos reclamar un empleo público moderno y eficaz, dados los retos a los que se enfrenta la Administración Pública. Aplicando los postulados de GIERKE, los empleados públicos son los brazos, ojos y cerebro de las Administraciones (22), y como resulta lógico, si a estas se les está exigiendo un comportamiento excepcional basado en la Gobernanza y otros conceptos relacionados con la mejora de las Administraciones Públicas, todo ello debe calar todavía

(20) Nos referimos al proyecto de Ley de la Función Pública, de 1999 (BOCG, Congreso de los Diputados, Serie A, de 5 de julio de 1999).

(21) PADILLA RUIZ, Pedro: Gestión del empleo público. La evaluación del desempeño en la mejora de la eficiencia administrativa, Bosch Editor, Barcelona, 2016. p. 41.

(22) Hemos de recordar aquí la Teoría del órgano de GIERKE, según la cual la Administración tiene personalidad propia y está investida de competencias, prerrogativas, derechos, deberes y obligaciones, que ejerce a través de órganos, que permanecen en el tiempo, siendo sus titulares, como personas físicas, un simple medio para lograr sus fines, actuando por cuenta de aquellos. Lo importante pues, no es la persona sino el puesto que ocupa, como conjunto de funciones y responsabilidades dentro de la organización, por lo que de acuerdo con esta idea las personas son mero instrumento para los fines de aquella. Sin perder de vista la limitación que esto supondría al papel de los empleados públicos, no podemos negar que son las personas quienes realizan las tareas que aqueIlas funciones representan, y su labor, bien la consideremos meramente instrumental o esencial, será tanto lo que cree la imagen que de la Administración tenga el ciudadano como el reflejo de lo que la misma está haciendo para que sus empleados sean mejores. La primera referencia que hace el citado autor a su Teoría del órgano es en VON GIERKE, Otto Friedrich. Die Genossenschaftstheorie und die deutsche Rechtsprechung, Weidmann, Berlín, 1887. En nuestro derecho es interesante la crítica que se hace de dicha teoría por SANTAMARÍA PASTOR, Juan Alfonso: "La teoría del órgano en el Derecho Administrativo", en Revista española de Derecho Administrativo, n. ${ }^{\circ} 40,1984$, pp. 43-86. 
más dentro del tejido administrativo y por capilaridad hasta llegar a quienes realmente y en su mayor parte constituyen lo que la Administración es: su personal.

El Informe de la Comisión para el estudio y preparación del EBEP hizo depender de los servidores públicos la existencia misma de una buena Administración (23), que además debe encontrarse presente en todas las etapas del sistema de empleo público: selección, formación, retribuciones... No puede ser de otra forma; los continuos cambios en la forma de ser y de actuar de la Administración y sobre todo en su relación con el ciudadano han llevado a reformar de manera seria (y esperemos que definitiva) el empleo como elemento esencial en toda esa compleja estructura cambiante.

Muy consciente de ello fue la Orden APU/3018/2004, de 16 de septiembre, por la que se constituyó la citada Comisión, al indicar en su justificación que:

"...debe producirse un paulatino cambio de cultura administrativa hacia una nueva cultura de gestión de los servicios públicos en la línea de los principios inspiradores de la gobernanza, entendiendo ésta como el modo de gestión característico de nuestra era: principio de la apertura y la transparencia, de la participación, responsabilidad, eficacia y coherencia.».

Y son esos principios los que, entre otros, forman parte de la buena Administración y deben empapar el empleo público(24). Para RODRíGUEZ-ARANA MUÑOZ, el ciudadano es la nota característica de la Administración(25). Por tal motivo la labor del empleado público adquiere un significado especial para dar una correcta atención a las demandas de aquel, cumpliendo a su vez los principios de la buena Administración.

El Informe de la Comisión tampoco dejó pasar la ocasión para destacar en su introducción la importancia del concepto, poniendo el énfasis

(23) SÁNCHEZ MORÓN, Miguel, CASES MÉNDEZ, José Ignacio, et al:: Informe de la Comisión para el estudio del Estatuto Básico del Empleado Público, INAP [versión electrónica], Madrid, 2005. p. 9.

(24) Podemos ver la relación eficacia-buena Administración la en la STS de 3 noviembre 2010 sobre reversión de un bien cedido por la Seguridad Social a una Comunidad Autónoma: «[...] otorgar el destino más conveniente posible desde el punto de vista de la eficacia y los principios de buena Administración (art. 4 del RDL 2/2004 de 16 de junio), y todo ello con pleno respeto al ejercicio de las competencias de una y otra Administración pública». F.J 2. ${ }^{\circ}$ También en la STS de 20 octubre 2011, F.J 4. ${ }^{\circ}$.

(25) RODRÍGUEZ-ARANA MUÑOZ, Jaime: El derecho a una buena administración para los ciudadanos: un modelo global de administración, Netbiblo, INAP, La Coruña-Madrid, 2013. p. 24. 
en la íntima relación existente entre una buena Administración y un empleo público de calidad ya desde el momento mismo de la selección, para lo cual se hace imprescindible contar no solo con los mejores profesionales sino que estos tengan unas motivaciones e incentivos que les permitan establecer un equilibrio adecuado entre sus derechos e intereses legítimos y sus deberes, obligaciones y responsabilidades, teniendo en cuenta que lo primordial es siempre garantizar el mejor servicio a la so$\operatorname{ciedad}(26)$.

En atención a este panorama general la Exposición de Motivos del EBEP también llamó la atención sobre ese gran objetivo de buena Administración en su cuarto párrafo al recordar que,

"Las Administraciones y entidades públicas de todo tipo deben contar con los factores organizativos que les permitan satisfacer el derecho de los ciudadanos a una buena Administración, que se va consolidando en el espacio europeo, y contribuir al desarrollo económico y social. Entre esos factores el más importante es, sin duda, el personal al servicio de la Administración.»

Se parte así del importante papel que adopta una adecuada estructura y organización en la prestación de todo aquello a que están obligadas las Administraciones para satisfacer ese derecho a la buena Administración. Esto no supone solamente un mero cumplimiento de las obligaciones de aquellas sino hacerlo de manera eficaz, transparente, etc. ahorrando recursos; todo lo cual, además, permite el meritado progreso en todos los ámbitos y no solo en el social y económico, pues el crecimiento económico y el desarrollo sostenible requieren que las Administraciones y toda su maquinaria sean fuertes, eficaces y eficientes, y por tanto que la Gobernanza y las diferentes formas de gestión pública colaboren en el logro de sus objetivos, como ha tenido ocasión de recordar la OCDE (27).

$Y$ como indica el párrafo transcrito, el factor humano se convierte en el elemento vertebrador de la actividad administrativa, en uno de los pilares esenciales de las Administraciones Públicas como un todo, por lo cual resulta obvio que la buena Administración, como mecanismo de excelencia en el logro de los resultados a que aspiran y como fin en sí mismo por

(26) SÁNCHEZ MORÓN, Miguel, CASES MÉNDEZ, José Ignacio, et al.: Informe de la Comisión para el estudio del Estatuto Básico del Empleado Público, INAP [versión electrónica], Madrid, 2005. p. 9.

(27) OCDE. Public Servants as Partners for Growth: Toward a Stronger, Leaner and More Equitable Workforce, OECD Publishing, Paris, 2011. p. 9. 
parte de aquellas, solo se consigue con una óptima organización y planificación estratégica, una adecuada conducta de sus miembros, así como con la evaluación y la mejora de su desempeño.

Podemos destacar lo que ya dijera SÁNCHEZ MORÓN sobre los problemas de funcionamiento de dicho sistema, que tal principio exige la profesionalidad de los servidores públicos y evitar riesgos tales como la excesiva politización, el clientelismo político, sindical o corporativista, la falta de productividad, el absentismo o la rigidez burocrática(28). La buena Administración y un óptimo sistema de empleo público no es solo eso pero pasa indefectiblemente por ello. $Y$ esa labor de mejora hasta lograr una Administración buena en el más amplio sentido de la palabra no depende únicamente de que su personal trabaje mejor, rinda más o esté motivado. Los poderes públicos, los cargos electos, los directivos y todos los que desde los niveles superiores de decisión están implicados en que el sistema funcione deben procurarlo de manera activa (29).

Para lograrlo ha de establecerse, obviamente, un sistema adecuado de carrera, ofrecer posibilidades de promoción a los empleados públicos, formarlos, motivarlos, crear una cultura administrativa que tantas veces falta, y por supuesto desarrollar sistemas de evaluación del desempeño como modo de mejora del trabajo de la Administración y de sus miembros. En particular, es necesaria primeramente voluntad política e imbuir al personal al servicio de las Administraciones de ese carácter de servicio a la sociedad dando ejemplo, creando políticas de recursos humanos realistas y ofreciendo confianza en que, entre todos los sectores implicados, se logrará poner de una vez a la Administración mirando hacia un mismo objetivo: el ciudadano(30).

(28) SÁNCHEZ MORÓN, M.: “Consideraciones generales sobre el Estatuto Básico del Empleado Público", en Justicia Administrativa, n. ${ }^{\circ} 36,2007$, pp. 5-23.

(29) SÁNCHEZ MORÓN, Miguel: "Comentarios al artículo 103»,en CASAS BAHAMONDE M. ${ }^{a}$ Emilia y RODRÍGUEZ PIÑEIRO Miguel (Dir.), Comentarios a la Constitución Española: XXX Aniversario, Fundación Wolters Kluwer, Madrid, 2008, pp. 1.682 y ss. p. 1686

(30) Una buena muestra de los requerimientos de coordinación, comunicación y entendimiento entre todos los niveles de la Administración Pública se plasma, por ejemplo en la AGE, en los acuerdos entre el Gobierno Central y los Sindicatos para la Función Pública en el marco del diálogo social. Concretamente, el aprobado para los años 2010-2012 se centró de manera especial en el logro de una administración moderna, racional, que promocione la carrera profesional, la formación, la igualdad, etc., y que comienza precisamente su contenido por la necesidad de impulsar la buena Administración, la modernización y la calidad de los servicios públicos.

Igualmente, el Acuerdo prevé el desarrollo del EBEP en lo que respecta a la aplicación del Código ético y de conducta del empleado público, así como del Sistema Integrado de Gestión de Personal y la aprobación de un Plan de Ordenación de Recursos Humanos, "que tendrá como objetivo contribuir a la mejor prestación de los servicios y a la utilización racional y eficiente de sus recursos materiales y tecnológicos".

Tampoco se olvida de la formación que «constituye una herramienta estratégica para la consecución de objetivos en el marco de un nuevo modelo productivo y de economía sostenible». 


\section{II.1. La conducta profesional y su conexión con el deber de buena Administración}

El principio de buena Administración tiene, quizás, su máxima expresión en el logro de esa Administración cercana, eficaz y eficiente a través del código de conducta profesional aprobado por el EBEP, como nexo de unión entre los fundamentos de dicho principio y la actuación del empleado público.

No se trata de la incorporación de los principios éticos y de conducta como consecuencia de la aplicación de la buena Administración, pues hemos de recordar que incluso antes siquiera de considerarse la misma como marco de actuación pública en nuestro ordenamiento ya se hacía necesario legislar sobre un código de conducta que estableciera los requisitos necesarios para un buen desempeño de los empleados públicos, dadas las funciones de defensa del interés general a que estaban llamados.

También hemos de recordar que si bien ya existían algunas menciones a la necesidad de respetar unas normas de conducta profesional, estas eran muy genéricas en sus postulados, sin que se hubiese dado hasta el EBEP un verdadero corpus de las mismas. En este sentido podemos recordar el artículo 80 de la Ley de Funcionarios Civiles del Estado, que solo hacía una breve referencia a la conducta en su artículo 80 disponía que,

"Los funcionarios han de observar en todo momento una conducta de máximo decoro, guardar sigilo riguroso respecto de los asuntos que conozcan por razón de su cargo, y esforzarse en la mejora de sus aptitudes profesionales y de su capacidad de trabajo.»

Lo que no puede negarse es que la aplicación de la buena Administración pasa necesariamente por la incorporación de un código ético y de conducta profesional que establezca un marco de actuación general, común y obligatorio para todos los empleados públicos y que permita ofrecer una actuación común ante el ciudadano(31), concretando unas pautas de comportamiento con el fin de dar respuesta adecuada a las exigencias de tal principio. En este sentido, coincidimos con RODRÍGUEZ-ARANA MUÑOZ al considerar que tal principio/derecho, contiene una indudable componente ética, que adquirió mayor relevancia durante la crisis ini-

(31) Aunque ciertamente, la descentralización que emana del EBEP y la posibilidad del legislador autonómico y estatal de decidir en cuanto a la conducta de sus empleados no ayuda a la creación de esa unidad en el servicio público. 
ciada hacia 2008(32). Por tanto, podemos concluir que buena Administración y código de conducta se complementan y convergen a la hora de dar respuesta a los desafíos del empleo público del siglo XXI.

Esa relación entre ambos elementos se reflejó, como indica MENDES, en el Código Europeo de Buena Conducta Administrativa de 2001, que constituye una guía de actuación tanto de las instituciones europeas como de sus órganos y funcionarios en sus relaciones con los ciudadanos (33), y que el EBEP introdujo en nuestro ordenamiento a través de los principios éticos y de conducta de los empleados públicos, teniendo como principal objetivo el desempeño diligente de las tareas encomendadas, velando por los intereses generales, actuando bajo una serie de principios que representan, en suma, la buena Administración (art. 52 y ss. EBEP).

Si bien es cierto que el código de conducta establece un marco general de desempeño profesional, incluyendo una amalgama de principios éticos y de conducta, podemos concretar de manera más específica la íntima relación existente entre aquel y la buena Administración dentro del procedimiento administrativo a través de ciertos principios, como pueden ser los de integridad, que resumiría todo aquello que se espera del empleado público (neutralidad, objetividad, transparencia...), accesibilidad, la persecución de la satisfacción del interés general, la buena fe, eficacia, economía y eficiencia, o el desempeño diligente de las tareas encomendadas.

Todo ello lleva aparejada una obligación especial de actuación personalizada en cada procedimiento para dar satisfacción a las necesidades concretas de los interesados, de manera que la suma de satisfacciones de estos con el servicio público recibido y con la actuación y conducta profesional de los empleados con los que interactúan denote la aplicación exitosa de la buena Administración.

Para finalizar, esa íntima relación entre esta y la actuación del empleado público se ha reflejado en la Ley $1 / 2015$, de 1 de abril, de garantía de la calidad de los servicios públicos y de la buena Administración, que destaca como principio de aquella la atención a la ciudadanía y cuyo artículo 3 define los derechos que la conforman, destacando en primer lugar el de recibir "un trato respetuoso, imparcial y sin discriminaciones", acorde con los postulados ya vistos al mencionar el código ético y de conducta.

(32) RODRÍGUEZ-ARANA MUÑOZ, Jaime: El derecho a una buena administración para los ciudadanos: un modelo global de administración, Netbiblo, INAP, La Coruña-Madrid, 2013. p. 12.

(33) MENDES, J.: "Good administration in EU law and the European Code of Good Administrative Behaviour", en EUI Working Papers Law, n. ${ }^{\circ}$ 9, 2009. p. 3. 


\section{II.2. La relación entre el derecho a una buena Administración y la evaluación del desempeño del empleado público}

La mal Ilamada evaluación del desempeño por el EBEP(34), regulada en su artículo 20, incluye resultados o rendimientos y conductas o desempeños stricto sensu, que en su conjunto permitirán saber si el empleado público, y por extensión la Administración, cumplen los criterios de calidad que se hayan fijado previamente mediante una adecuada planificación estratégica y de recursos humanos. En tal sentido, y puesto que la evaluación no es, ni más ni menos, que una herramienta que aporta información valiosísima para conocer si el empleado está haciendo bien su trabajo y de acuerdo con los parámetros fijados, podemos concluir sin temor a equivocarnos que esta institución constituye un elemento esencial para la medición del grado de cumplimiento de la buen Administración.

Hemos de reiterar la importancia fundamental que el factor humano tiene en la consecución de los objetivos de las organizaciones públicas, desde la planificación de políticas públicas hasta la satisfacción de la necesidad concreta del ciudadano individual. Desde el punto de vista del empleo público, su adecuada planificación y gestión se tornan en elementos esenciales para el éxito de aquellas políticas. Por su parte, la evaluación del desempeño, como área o función de dicha gestión, se convierte en un elemento de primer orden en la consecución de los postulados de la buena Administración, siendo así porque desde nuestro punto de vista constituye -además - elemento central en dicha planificación por la información que ofrece para llevar a cabo sus objetivos,

Y puesto que la ejecución de sistemas de evaluación del desempeño requiere de una planificación adecuada y del establecimiento de las dimensiones e indicadores necesarios para llevarlos a cabo, la correcta aplicación de este principio pasa también porque cada Administración sepa exactamente lo que quiere, cuáles son sus puntos fuertes y áreas de mejora y qué elementos de la actuación del empleado público quiere reforzar o mantener (dentro de la consecución del conjunto de sus obligaciones) para dar cumplimiento al marco de derechos ciudadanos establecido por la buena Administración.

Con ello no estamos diciendo que deba darse más prioridad a unos derechos sobre otros, sino precisamente que, dentro de la correcta garantía de todos ellos, todo sistema de evaluación debe centrarse en re-

(34) Nos referimos a que desempeño, en sentido estricto, hace referencia a la conducta profesional, si bien, como convención, se ha considerado generalmente el término evaluación del desempeño con un carácter amplio, incluyendo tanto aquella como los resultados o rendimientos. También suele conocerse como evaluación del rendimiento. 
cabar información sobre aquellos puntos que la planificación considera de mayor importancia o que hay que reforzar tras un estudio de las necesidades que más preocupan al ciudadano, tanto en lo relativo a resultados cuanto a trato personal. Y esto tiene mucho que ver con un requisito esencial de todo modelo de evaluación que veremos más adelante, la relevancia.

Partiendo de la consideración de que el modo en que actúan los empleados públicos (cómo hacen su trabajo, frente a qué hacen) constituye uno de los fundamentos del principio de buena Administración - aunque no es el único-y de que la conducta profesional es, precisamente, uno de los dos objetos de la evaluación del desempeño, cabe ahora realizar una breve aproximación a la concreta relación existente entre dicho principio y la evaluación de aquella.

EI EBEP ha considerado que junto con la obtención de rendimientos y resultados el otro factor central para conseguir una Administración eficaz, eficiente y «buena» es tener en cuenta la conducta del empleado público. Y ello es así porque la satisfacción del ciudadano con los servicios públicos no solo se expresa a través de la correcta y pronta respuesta a sus necesidades; se refleja también, y de manera especial, en el trato que recibe de los empleados públicos. Todo ello, en conjunto, da lugar a la valoración que el ciudadano tiene de los servicios públicos y no tanto de los empleados que le hayan atendido, con lo que las Administraciones deben prestar una atención especial a la forma de actuar de estos.

El modo de evaluar la conducta es complejo por estar íntimamente relacionada con la psicología humana y encontrarse sometida a una serie de sesgos que dificultan sobremanera su buena ejecución. Por ello, lograr una gestión de personas que dé respuesta a los postulados de la buena Administración es complicado, pero queremos también insistir en la necesidad de aplicar sistemas de evaluación del desempeño en nuestras Administraciones, no solo porque con ella se podrá mejorar la eficacia y eficiencia de la propia gestión del personal sino sobre todo, y como objetivo más amplio, se estarán alcanzando las exigencias de aquel principio, que a la vez tratan de lograr esa misma Administración eficiente y eficaz, produciéndose un óptimo círculo que nos lleva a considerar que a través de la evaluación del desempeño se mejora la gestión del personal de las Administraciones Públicas, lo que al mismo tiempo servirá para alcanzar un mejor servicio público, consiguiendo dar cumplimiento al principio de buena Administración.

Respecto a la evaluación de resultados y rendimientos nos encontramos con una situación similar aunque por su carácter más objetivo es quizás más fácil de evaluar y por tanto de comprobar su adecuación a los criterios exigidos por la buena Administración. Rendimientos y resultados sí pueden conectarse más sencillamente con las exigencias más claras 
que establece el procedimiento administrativo y una respuesta directa a las necesidades del ciudadano (sin menospreciar el trato), pues suelen aplicarse varias dimensiones que reflejan preocupaciones constantes de aquel en todo procedimiento: tiempo (celeridad), coste y cantidad. La mejora de los resultados de la evaluación en estas dimensiones es un reto constante para cualquier Administración y una buena manera de medir su eficacia y eficiencia.

Ahora bien, vistos los dos elementos esenciales que configuran el objeto de la evaluación debemos mencionar uno de sus requisitos, la relevancia, que afecta a lo que se pretenda conseguir con cualquier sistema evaluador. PADILLA RUIZ recuerda que se trata de uno de los requisitos esenciales de todo sistema de evaluación del desempeño, por el que únicamente se deberán valorar aquellas tareas significativas (relevantes) de la actuación del evaluado(35). Habrá que restringir aquella primero a lo que esté en la mano del empleado, lo que dependa de su desempeño personal y no de otros; y además tiene que ser una tarea relevante, no cualquier cosa que realice. Hay que priorizar e ir a lo importante y necesario para saber de manera fiable si se cumple con lo esperado y por tanto si se aplica correctamente el principio de buen Administración.

Por tanto, podemos concluir que la evaluación del desempeño se torna en un apoyo imprescindible para dar cumplimiento al principio de buena Administración pues aquella, atendiendo a los aspectos más relevantes del trabajo de los empleados públicos, responde perfectamente a sus exigencias al tener presente todo cuanto esta exige en su desempeño profesional, tanto desde el punto de vista de la conducta cuanto del rendimiento.

\section{Conclusiones}

La introducción del principio de buena Administración en el ordenamiento jurídico denota una vez más las grandes carencias que vienen arrastrando nuestras Administraciones Públicas desde hace décadas, unas de carácter estructural y otras debidas en parte a los nuevos desafíos con que se encuentran para dar respuesta a los cada vez más rápidos avances de la sociedad.

Consideramos la buena Administración como un marco en el que se engloban una serie de derechos del ciudadano y coetáneas obligaciones de las Administraciones y empleados públicos, configurado como un

(35) PADILLA RUIZ, Pedro: Gestión del empleo público. La evaluación del desempeño en la mejora de la eficiencia administrativa, Bosch Editor, Barcelona, 2016. p. 70 y ss. 
principio o marco general de actuación que trata de dar mayor consistencia a esa necesidad de actuar conforme a los principios éticos y de conducta en que se plasma, sin perder de vista los derechos y garantías concretos que deben respetarse dentro del procedimiento administrativo.

Con objeto de dar cumplimiento a los tan ansiados objetivos de eficacia y eficiencia administrativa el legislador del EBEP por fin fue consciente de la importancia de aplicar los principios de la buena Administración en el empleo público. Con el fin de ofrecer un marco imprescindible para el buen desempeño de los empleados públicos se crearon los principios éticos y de conducta, que si bien no son los únicos elementos a tener en cuenta sí al menos constituyen una herramienta necesaria para explicar dicho principio.

Además, con este código se ofrece un imprescindible apoyo a la fundamental institución de la evaluación del desempeño en su faceta de control sobre cómo realiza su trabajo el empleado público, algo imprescindible para poder medir ese desempeño stricto sensu, a la vez que se logra el mencionado punto de partida para el logro de la Administración eficiente y preocupada por el interés general que todos queremos.

Finalmente, no hay que perder de vista que la buena Administración también se fundamenta en los aspectos o derechos más objetivos de cuanto hace el empleado público dentro del procedimiento administrativo, como los resultados y rendimientos. Estos forman parte también consustancial de la evaluación del desempeño, reforzando así su estrecha relación, formando un círculo entre el empleado público, su evaluación y el logro de la buena Administración.

\section{Bibliografía}

AMILIVIA GONZÁLEZ, Mario y NALDA GARCÍA, José C.: «Principios de buena Administración y función consultiva", en Revista española de la función consultiva, n. ${ }^{\circ}$ 9, 2008, pp. 17-30.

ÁVILA RODRíGUEZ, Carmen María y GUTIÉRREZ RODRÍGUEZ, Francisco J.: El derecho a una buena Administración y la ética pública, Tirant lo Blanch, Valencia, 2011.

BAENA DEL ALCÁZAR, Mariano: Curso de Ciencia de la Administración, Vol. I, 4. ${ }^{\text {a }}$ edic., Tecnos, 2000.

CARRILLO DONAIRE, Juan Antonio: «Buena administración, ¿un principio, un mandato o un derecho subjetivo?», en SANTAMARÍA PASTOR Juan Alfonso (Dir.), Los principios jurídicos del Derecho Administrativo, La Ley, Madrid, 2010, pp. 1137-1165.

CERRILLO I MARTÍNEZ, Agustí: La gobernanza hoy: 10 textos de referencia, 1. ${ }^{\text {a }}$ edic., INAP, Madrid, 2005. 
DÍAZ MUIÑA, Manuel y MURILLO GARCÍA-ATANCE, Ignacio: "La ética administrativa: elemento imprescindible de una buena Administración», en Revista Aragonesa de Administración Pública, n. ${ }^{\circ} 32,2008$, pp. 133-170.

DÍAZY DÍAZ, María Cruz: El empleado público ante el procedimiento administrativo: deberes y obligaciones de buena administración, La Ley. Grupo Wolters Kluwer., 2011.

FUENTETAJA PASTOR, Jesús Angel: «El derecho a la buena administración en la Carta de los Derechos Fundamentales de la Unión Europea», en Revista de derecho de la Unión Europea, n. ${ }^{\circ} 15,2008$, pp. 137-154.

GÁMEZ GÁMEZ, José Antonio: El derecho a una buena Administración desde la perspectiva de la ética pública: el buen gobierno y la buena conducta administrativa, 2009.

GUILLEM CARRAU, Javier: "La buena administración en la UE tras el Tratado de Lisboa: ¿más por menos?», en Corts: Anuario de derecho parlamentario, n. ${ }^{\circ} 25,2011$, pp. 69-103.

LORENZO DE MEMBIELA, Juan B.: "La buena administración como estrategía promotora de la excelencia gestora», en Revista Aragonesa de Administración Pública, n. ${ }^{\circ} 30,2007$, pp. 445-458.

LORENZO DE MEMBIELA, Juan B.: "La buena administración en la Administración General del Estado", en Actualidad administrativa, n. ${ }^{\circ} 4,2007$, pp. 405-414.

MEILÁN GIL, José Luis: "La buena Administración como institución jurídica», en Administración de Andalucía: revista andaluza de administración pública, n. ${ }^{\circ} 87,2013$, pp. 13-50.

MENDES, J.: "Good administration in EU law and the European Code of Good Administrative Behaviour", en EUI Working Papers Law, n. ${ }^{\circ}$, 2009.

OCDE.: Public Servants as Partners for Growth: Toward a Stronger, Leaner and More Equitable Workforce, OECD Publishing, Paris, 2011.

PADILLA RUIZ, Pedro: Gestión del empleo público. La evaluación del desempeño en la mejora de la eficiencia administrativa, Bosch Editor, Barcelona, 2016.

PONCE SOLÉ, Julio: Deber de buena Administración y derecho al procedimiento administrativo debido: las bases constitucionales del procedimiento administrativo y del ejercicio de la discrecionalidad, 1. $^{\text {a }}$ edic., Lex Nova, Valladolid, 2001.

RODRÍGUEZ-ARANA MUÑOZ, Jaime: El derecho a una buena administración para los ciudadanos: un modelo global de administración, Netbiblo, INAP, La Coruña-Madrid, 2013.

RODRÍGUEZ-ARANA MUÑOZ, Jaime: «El derecho fundamental a la buena Administración en la Constitución española y en la Unión Europea», en REGAP: Revista galega de Administración Pública, n. ${ }^{\circ} 40,2010$, pp. 235-264. 
RODRÍGUEZ-ARANA MUÑOZ, Jaime: «Ética pública y buena Administración de instituciones públicas", en Revista de estudios locales. Cunal, n. ${ }^{\circ} 98,2007$, pp. 14-21.

RODRÍGUEZ-ARANA MUÑOZ, Xaime: «El derecho fundamental al buen gobierno y a la buena Administración de instituciones públicas», en Revista de derecho público, n. ${ }^{\circ} 113,2008$, pp. 31-42.

SÁNCHEZ MORÓN, M.: "Consideraciones generales sobre el Estatuto Básico del Empleado Público», en Justicia Administrativa, n. ${ }^{\circ} 36,2007$, pp. 5-23.

SÁNCHEZ MORÓN, M.: "Comentarios al artículo 103», Casas Bahamonde M. ${ }^{a}$ Emilia y Rodríguez Piñeiro Miguel (Dir.), Comentarios a la Constitución Española: XXX Aniversario, Fundación Wolters Kluwer, Madrid, 2008, pp. 1.682 y ss.

SÁNCHEZ MORÓN, Miguel, CASES MÉNDEZ, José Ignacio, et al.: Informe de la Comisión para el estudio del Estatuto Básico del Empleado Público, INAP [versión electrónica], Madrid, 2005.

SANTAMARÍA PASTOR, Juan Alfonso: "La teoría del órgano en el Derecho Administrativo", en Revista española de Derecho Administrativo, n. ${ }^{\circ} 40$, 1984, pp. 43-86.

TOMÁS MALLÉN, Beatriz: El derecho fundamental a una buena administración, 1. ${ }^{\mathrm{a}}$ edic., INAP, Madrid, 2004.

TORNOS MAS, Joaquín: El derecho a una buena administración [recurso electrónico], Barcelona, Sindicatura de Greuges de Barcelona, 2007

VILLORIA MENDIETA, Manuel. La modernización de la Administración como instrumento al servicio de la democracia, INAP, Madrid, 1996.

VON GIERKE, Otto Friedrich: Die Genossenschaftstheorie und die deutsche Rechtsprechung, Weidmann, Berlín, 1887. 
LABURPENA: Herritarrei emaitza onak eskaintzeko orduan, Administrazio Publikoa ez dute beti gidatu izan bere xede eta betebeharrekin bat egiten duten jarduera-ereduek, eta administrazio txarra deritzona ekarri du horrek. Horren ondorioak ahultzeko, administrazio ona edukitzeko eskubidea eta administrazio onaren printzipioa agertu ziren, administrazioak jarduteko esparru gisara. Hala ere, enplegatu publikoek jarduteko esparrua izateko sortu ziren batez ere, horiexek baitira gizarteak eskatzen duen administrazioaren benetako egileak.

Kontzeptu horretara hurbildu ondoren, eta hortik abiatuta, printzipio horren eta enplegatu publikoek kalitateko administrazioa lortzeko egiten duten jardueraren arteko harremana aztertuko dugu. Zehazki, printzipioak enplegatuen jarrera profesionalarekin eta lanaren gaineko ebaluazioarekin duen lotura aztertuko dugu; izan ere, ebaluazio hori funtsezko tresna da, administrazio on horren betetze-maila egiaztatzeko informazioa ematen du-eta.

GAKO HITZAK: Administrazio ona. Enplegatu publikoa. Lanaren ebaluazioa. Eraginkortasuna. Efizientzia.

RESUMEN: La Administración Pública no siempre se ha guiado por modelos de actuación acordes con sus objetivos y obligaciones a la hora de ofrecer resultados satisfactorios a los ciudadanos, dando lugar a lo que se ha venido en llamar una mala Administración. Para contrarrestar sus defectos apareció el derecho-principio de buena Administración como marco de actuación de aquella, pero sobre todo de los empleados públicos, verdaderos artífices de la Administración que reclama la sociedad.

Partiendo de una aproximación a tal concepto, analizamos la relación existente entre dicho principio y la actuación del empleado público para el logro de una Administración de calidad, abordando en particular su conexión con la conducta profesional y con la evaluación del desempeño, herramienta esencial, por otra parte, por la información que ofrece a la hora de comprobar el grado de cumplimiento de esa buena Administración.

PALABRAS CLAVE: Buena Administración. Empleado público. Evaluación del desempeño. Eficacia. Eficiencia.

ABSTRACT: Public Administration has not always been guided by models of action according to its objectives and duties in order to offer satisfactory results to the citizens. This has gave rise to what it has been called a bad Administration. In order to counteract its shortcomings the right-principle of good Administration has appeared as a framework of the Administration action, but above all of the public employees, real authors of the Administration that the society demands.

On the basis of an approach to this concept we analyze the existing relationship between this principle and the public employee performance in order to achieve the quality in the Public Administration, addressing, in particular, its con- 
nection with professional behaviour and job evaluation, which is an essential tool, on the other hand, due to the information it offers to verify the degree of compliance of that good Administration.

KEYWORDS: Good Administration. Public Employee. Job evaluation. Efficacy. Efficiency. 